\title{
Student Perceptions Of And Preferences For A Short Overseas Study Tour
}

Joel Evans, Youngstown State University Janel Finch, Youngstown State University

Mark F. Toncar, Youngstown State University

Jane S. Reid, Youngstown State University

\begin{abstract}
Business programs and colleges of business have responded to calls from both AACSB and industry with many different methods of internationalizing business curricula. One increasingly popular method of exposing business students to international issues is the short study tour. This research investigates student perceptions of and preference for, different aspects of a short study tour. Students at a medium-sized metropolitan university in the Midwest were asked to complete a survey. Results suggest that for the students involved in this research, cost is the most important criteria, followed by the country or countries in which the tour will take place. Students recognize the value of short study tours, and seem prepared to pay a reasonable price for the appropriate experience. The paper concludes with a discussion of the value of study tours to developed versus emerging market countries.
\end{abstract}

\section{INTRODUCTION}

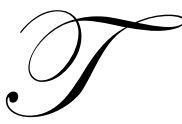

he increasingly global face of business highlights the importance of providing business students with a global perspective in their education. Curricula initiatives around the country have resulted in substantially greater emphasis on international business issues. One effective way to provide business students with this global perspective is through study-abroad programs. Such programs have taken a variety of forms, from two-week study tours to two-month internships to semesters or entire academic years studying abroad. The purpose of this paper is to investigate student perceptions of short study tours at one mid-sized Midwestern university.

Study abroad programs vary in terms of the duration, objectives, and the time of year offered. And each of these characteristics directly influences the program cost. The longer the scheduled program, the more expensive housing and other living expenses become. The more ambitious the program objectives are in terms of travel itineraries, tours, etc. the greater the cost. And programs that are offered during traditional tourist seasons are likely to be substantially more expensive, in terms of air fare and accommodations than program offered during off-peak times. It is therefore necessary, in times of limited resources, to balance the ideal with the pragmatic so as to develop and offer a program that will meet the educational objectives of the program within the often severe financial constraints of students.

Toward that end, this research explores what characteristics students desire in a short (10-14 day) study tour, as well as the relative importance of each. Developing a program that prospective students perceive as useful and valuable will enhance the probability of successfully operating a short term study tour.

\section{LITERATURE REVIEW}

Study-abroad programs are not new. Once dubbed "a gentleman's education" (Campbell, 2003, p. 2), students across the U.S. are discovering the value of leaving their culture behind. According to Balkan (2003), "travel abroad is especially important for Americans; we have it drilled into us early that the best of everything is rightly ours. We think big, dream big, are big. We are even endowed with the right to pursue happiness--what a 
concept; try finding a feeling of entitlement to happiness engrained in the citizenry anywhere else in the world," (p. 4). Peden (2001) presents five benefits that college students receive from study-abroad programs including: (1) academic credit, (2) language credit, (3) practical experience, (4) résumé building, and (5) an experience of a lifetime. LaFranchi (2003) admits that for some students the motivation to study abroad is to have fun, see the world, escape the paper chase for a semester, and leave the confines of home. He (2003) adds that a lot of students are seeking to spice up their résumés with global experiences to give them the edge in a competitive job market, and lastly, students are seeing firsthand how the United States and its citizens are perceived in other countries. Praetzel and Curcio (1996) indicate that, "study abroad fosters improved understanding of foreign cultures, people, and institutions, develops more open mindedness and tolerance, instills greater confidence, and promotes faster maturation," (pp. 177-178).

With regard to business programs, Praetzel and Curcio (1996) reported that while everyone from the faculty to accrediting bodies of business programs agreed that international issues were essential to a business education, very little had been accomplished in making it so. "Evidence from various sources supports this contention, including comprehensive studies of business schools, evaluations of textbook content, and, less formally, feedback from Niagara University students," (Praetzel and Curcio, 1996, p. 174). They (1996) conclude that, "a student in a professional program must be cognizant of international issues and possess the sensitivity to work in a diverse environment characterized by an alternative set of cultural, historical, political, social, religious, and economic issues," (Praetzel and Curcio, 1996, p. 175). The authors (1996) feel that one of the best ways to internationalize the business program is through study abroad and suggest that faculty buy-in and participation are critical to program success.

Albers-Miller, Prenshaw, and Straughan (1999) basically stated that U.S. business schools ignored the international community until foreign competition increased the demand for graduates who knew something about international business. "Colleges of Business were ill-prepared to fill the demand for international education. The internationalization of the curriculum was far behind Business Schools in other countries" (Albers-Miller et al., 1999, p. 29). This quest for internationalizing the curriculum is taking several forms including overseas internships, exchange programs, faculty development, joint ventures, and study abroad (Albers-Miller et al., 1999). While the literature suggests that study-abroad programs are beneficial to all students, business students, in particular, need exposure to the global business environment. As Festervand and Tillery (2001) point out, the business accrediting body, AACSB, has included not only the coverage of international aspects of business in courses but also with the professional development of faculty. They cite several benefits for faculty in participating in an international experience including: (1) academic validation by grounding concept and theory into reality, (2) intellectual growth by acquiring new knowledge, (3) acculturation and correction of biases and stereotypes, (4) academic administration by being put in charge of funding, scheduling, and making arrangement for the program, and (5) cognitive repositioning or a "dose of humility" (Festervand and Tillery, 2001, p. 110).

Albers-Miller et al., (1999) queried business students and found that only 35.2 percent of them would take an international course if it was not required; however, they also found that the same students' perceptions of a study-abroad program were favorable. The students considered study-abroad programs fun, beneficial, a good experience, and would help them get a job upon graduation, but only 41.2 percent had seen information about their university's study abroad programs and only 17.3 percent knew a lot about the program while 29.6 percent did not know that a program existed. Their business students raised concerns about the time and cost of the study-abroad program would take as well as it preventing them from graduating on time. They did seem to prefer shorter length programs than longer programs.

Previous research by Toncar and Reid (2004) has explored business student perceptions and preferences of study abroad programs. Their work focused on a comparison of short study tours with longer programs such as internships and semesters abroad. Their results indicated that business students preferred a short, several week-long program, completed under the supervision of faculty. The purpose of this research is to explore the specific aspects of short study tours that are more or less attractive to business students. 


\section{METHOD}

A quota sample was used to insure adequate representation of men and women, as well as students of all class ranks (freshman sophomore, etc.) and majors in the college of business. The survey began with five semantic differential scaled items to determine students' general perceptions of business study tours. The paired adjectives used in the survey appear in Table 1. Students responded on a six point scale, eliminating the opportunity for students to choose a neutral point. These were followed by 15 scaled items designed to assess student perceptions of and preferences for more specific aspects of short study tours. Students were asked to express their level of agreement with a series of statements on a four point scale anchored by strongly agree (1) and strongly disagree (4). This was followed by a "build your own program" exercise that consisted of eight multiple choice questions asking students to describe their "ideal" short study tour. Several demographic questions were then asked for classification purposes.

One hundred and three students at a medium-sized metropolitan university in the Midwest completed the survey. Fifty respondents were women and 53 were men. The age of the students ranged from $18-44$ with an average age of 22.7. Sixteen freshman, 10 sophomores, 30 juniors, 37 seniors, and 10 graduate students completed the survey. Most, 97 were full-time students, five were part-time students, and one did not report. Fifty-nine reported they worked part-time, 29 worked full-time, and 15 were not employed. Finally, 23 students reported that they had a passport, while 80 did not.

\section{RESULTS}

Subjects' responses to the five general perception questions are summarized in Table 1. Overall, students reported generally favorable perceptions of business study tours. Given that responses could range from one to six, the midpoint on the scale is 3.5. With the exception of the "Expensive v. Affordable" pair, all mean responses fell to the "favorable" side of the midpoint. Students appeared to believe strongly that these programs are both educational and worthwhile, and that they are both exciting and relatively safe. However, the programs are perceived - perhaps correctly, as relatively expensive.

Table 1

General Perceptions of Business Study Tours

\begin{tabular}{lccc}
\hline \hline \multicolumn{1}{c}{ Scale Anchor Points } & Minimum & Maximum & Mean \\
\hline 1. Safe v. Dangerous & 1 & 6 & 2.29 \\
2. Expensive v. Affordable & 1 & 6 & 2.49 \\
3. Exciting v. Boring & 1 & 5 & 2.21 \\
4. Educational v. Uninformative & 1 & 5 & 1.96 \\
5. Worthwhile v. Waste of Time & 1 & 5 & 2.06 \\
\hline
\end{tabular}

The more specific statements relating to business study tours, summarized in Table 2, provide useful insights into the issues that appear to be most important to the students in the sample. Responses could range from one to four, with a midpoint of 2.5. Therefore, scores below/above 2.5 can be cautiously interpreted as being in agreement/disagreement with the statement. Similarly, the larger the mean score deviates from the midpoint, the greater the presumed level of agreement/disagreement.

A careful inspection of the means suggests that the statements can be somewhat arbitrarily placed into perhaps three categories, based on the magnitude of the difference between the midpoint of 2.5 and the mean score. The first includes those items whose mean score deviates from the midpoint by roughly .50 point or more, indicating strong agreement/disagreement with the associated statement. Eight of the 15 items fall into this category; 8, 9, 10, 14, 16, 18, 19 and 20. The second group consists of those items with mean scores that indicate mild agreement/disagreement with the associated statements. These include items $6,12,13$ and 17. Finally, those items 
whose mean scores are very close (roughly .10 or less) represent a third category. These include items 7, 11 and 15. The mean scores as well as the absolute value of the deviations from the midpoint appear in Table 2.

Looking at the items that students appeared to feel the most strongly about, it seems that the items represent both financial concerns and concerns about safety and familiarity. Specifically, items 9, 16 and 18 are directly related to financial issues; financial aid, academic credit and reasonable prices, while items 8, 10, 19 and 20 appear to be directly or indirectly related to students' familiarity and comfort level. Students expressed a clear preference for programs with clearly spelled-out itineraries operated by faculty that they know, that include other student travelers, where English will be widely spoken.

Of lesser concern are issues that might be considered somewhat more pragmatic in orientation. Among these are student perceptions of the effect of a study tour on future job opportunities, the likelihood of getting time off work to participate, restrictions on who is permitted to participate in study tours and the time of year most appropriate. And while the perceived importance of these issues varied, none of these issues seemed to arouse the intensity of the responses that pertained to familiarity and money.

With regard to the "build your own program" exercise, a relatively clear picture emerged regarding what students would like to see as part of a business study tour. Students were asked when they prefer to travel, how much they would expect to pay for their "perfect" program, how much input they would like to have in determining the specifics of the program, whether they felt they were prepared for an overseas study tour, the relative importance of five characteristics of the trip (friends attending, cost, cities/countries visited, business visited and leisure/free time available), and finally whether they would go on their "perfect" study tour if it were offered.

The profile that emerged from the responses is summarized in Table 3. As illustrated in the table, a majority of students preferred to: a) travel in the summer; b) have some input into the program content; c) were very concerned about the cost; d) believed they were prepared to travel abroad; and e) were willing to participate if their ideal program were offered.

Table 2

Specific Perceptions of and Preferences for Business Study Tours

\begin{tabular}{|c|c|c|}
\hline Statement & $\begin{array}{l}\text { Deviation from the } \\
\text { Midpoint (2.5) }\end{array}$ & Mean \\
\hline 6. I have heard about study tour opportunities through the WCBA & .24 & 2.26 \\
\hline 7. Most YSU students are not interested in traveling on a study tour & .11 & 2.61 \\
\hline $\begin{array}{l}\text { 8. Knowing the faculty member(s) that is accompanying the study tour makes it } \\
\text { more attractive to me }\end{array}$ & .65 & 1.85 \\
\hline $\begin{array}{l}\text { 9. If the business school offered reasonably priced study abroad programs, I would } \\
\text { take advantage of them }\end{array}$ & .63 & 1.87 \\
\hline 10. I would prefer to go on a study tour where English is not widely spoken & .49 & 2.99 \\
\hline 11. I could not get the time off work to go on a study tour & .10 & 2.60 \\
\hline $\begin{array}{l}\text { 12. Assuming the study tours are the same length I would be more interested in } \\
\text { traveling in the summer than in the school year }\end{array}$ & .32 & 2.18 \\
\hline 13. Any student, regardless of grade, should be allowed to attend the study tour & .20 & 2.30 \\
\hline 14. Any student, regardless of rank, should be allowed to attend the study tour & .54 & 1.96 \\
\hline 15. My parents would be worried for my safety if I went on a study tour & .02 & 2.52 \\
\hline 16. I would not participate in a study tour unless it included academic credit & .62 & 1.88 \\
\hline 17. Traveling on a study tour would not affect my future job opportunities & .28 & 2.78 \\
\hline $\begin{array}{l}\text { 18. The business college should offer extra financial aid for students traveling } \\
\text { abroad on study tour }\end{array}$ & .97 & 1.53 \\
\hline $\begin{array}{l}\text { 19. Knowing the study tour itinerary before registering would encourage students to } \\
\text { go }\end{array}$ & .96 & 1.54 \\
\hline $\begin{array}{l}\text { 20. I would be more comfortable in going on a study tour if I knew other students } \\
\text { that were going as well }\end{array}$ & .93 & 1.57 \\
\hline
\end{tabular}


Table 3

"Build Your Own Program" Summary

\begin{tabular}{ll}
\hline \hline Characteristic & Responses \\
\hline When would you go? & Summer $(52 \%)$ winter $(25 \%)$ \\
How much would you pay? & Mean: $\$ 1089 ;$ range; $0-\$ 8,000 ; 63 \%$ willing to pay \\
& $\$ 1,000$ or more; $25 \%$ willing to pay $\$ 1500$ or more; \\
& $3 \%$ willing to pay over $\$ 2,000$ \\
How much input would you like to have? & $85 \%$ said they would like to help choose the business \\
& visits \\
What study tour attributes matter the most to you? & 53 ranked most important \\
Cost & 35 ranked most important \\
Cities/Countries visited & 11 ranked most important \\
Friends attending the study tour with you & 3 ranked most important \\
Businesses visited & 2 ranked most important \\
Leisure/free time & $68 \%$ yes; 32\% no \\
Do you feel prepared for a study tour & $96 \%$ yes \\
Would you travel on your "perfect" study tour? & \\
\hline
\end{tabular}

Finally, students were asked to list the three countries that they would be most interested in visiting on a study tour. The responses are summarized in Table 4. It is interesting to note that three are English-speaking countries and only one country, China, is an emerging market, developing country. This brings up interesting implications to faculty and administrators who are developing and operating study tours and is discussed subsequently.

Table 4 Most Popular Country Choices

\begin{tabular}{cc}
\hline \hline Country & Number of times listed \\
\hline Italy & 52 \\
England & 38 \\
France & 34 \\
China & 23 \\
Germany & 21 \\
Australia & 20 \\
Japan & 17 \\
Ireland & 14 \\
\hline
\end{tabular}

\section{DISCUSSION}

There is little question that students and faculty can benefit enormously from short study tours. They offer flexibility, in that they can take place between semesters, during spring break, or in the summer months. And they are often far less costly than other study abroad options, because of reduced food and lodging expenses arising from short duration tours. The authors' interest in this area is due in large part to the benefits that we have received as both students and faculty. Surveys that assess the perceptions and preferences of potential program participants provide valuable information and insights to the organizers and operators of overseas study tours.

These results not only offer useful insights into program development, but also suggest that some interesting choices may be necessary to develop and operate a successful study tour. For example, cost was clearly the most import concern for students. Fifty-three students indicated that cost was their number one concern. When one inspects the data related to cost, a significant minority, $25 \%$, are willing to pay $\$ 1,500$ or more for a study tour a price that, based on prior experience by the authors, is an attainable program cost. While this eliminates $75 \%$ of the total student market, it represents a significant number nonetheless. Interestingly, of the 25 students who reported they would pay $\$ 1,500$ or more, 11 said they would pay $\$ 1,500$, and 11 said they would pay $\$ 2,000$. For 
this sample, it seems that the $\$ 1,500-\$ 2,000$ range represents the "sweet spot," the price point at which a program is both attractive and reasonably priced from the student perspective, and realistic from an organizational standpoint.

However, the second most important concern, mentioned by 35 students, was the country or countries visited, with the developed countries of Italy, England and France listed by 52, 38 and 34 students respectively. Herein lies a dilemma. As business educators, we recognize the importance of emerging market countries, such as BRIC - Brazil, Russia, India and China, and the role that emerging market countries will play in the $21^{\text {st }}$ century global economy. And the argument can be forcefully made that it is in the best interests of our students that these countries be selected as the destinations for study tours. However, the data reported here suggests that may be a recipe for failure. Students express a very clear preference for a study tour to developed countries. And given the fact that at most $25 \%$ of the students represent a viable market from a cost standpoint, study tour organizers may be faced with a choice of offering an exciting educational experience to an emerging market country that may not attract sufficient numbers of students, or offering a more mundane and comfortable study tour to a developed country that is likely to attract a larger number of participants.

This dilemma has provoked vigorous debate. Proponents of emerging market study tours argue correctly that future growth for U.S. business will be in the emerging market countries, and that we are doing a disservice to our students if we do not provide them with the opportunity to experience cultures and business customs in these emerging markets. However, proponents of developed country-based study tours often make the case that students who travel on study tours to developed countries would not participate in study tours to emerging market countries. If this is true, then providing these students an overseas experience - even one that is not as relevant or challenging, still represents an enormous opportunity for learning and personal growth. In short, a study tour to a developed country is better than no study tour at all.

We would argue that both options can be appropriate, under certain conditions. We would also suggest that the appropriate study tour destination depends largely on the overall study tour objectives. Study tours are not generic, and in fact vary enormously. Study tours to the BRIC countries are very valuable for those students who are prepared for the challenges that may accompany such a study tour. Study tours to developed countries may be more suitable for students who are less cosmopolitan, more risk averse, students with complex medical issues or concerns, or who are not accustomed to overseas travel.

There are also complex interactions between costs and countries. Emerging market countries, notably India and China, require long, expensive flights, and possibly an additional day of acclimation to different time zones. However, this increased cost is, in some cases somewhat offset by a comparatively lower cost of living in the host country. Conversely, air travel to developed countries is often less expensive, but these saving can be lost to cost of living and unfavorable currency exchange rates.

In summary, this research suggests that students have fairly clear preferences and concerns with regard to short study tours. Large schools with adequate funding may be able to develop and offer short study tours that accomplish specific educational objectives with little regard for the specific perceptions and preferences of students. However, small colleges and universities, schools with severe budget limitations or who serve relatively less affluent markets, as well as schools whose students are less cosmopolitan, may need to give greater consideration to the student as customer, and develop study tours that, to some extent satisfy the needs and desires of these customers while still meeting specific educational objectives.

\section{REFERENCES}

1. Albers-Miller, Nancy D., Prenshaw, Penelope P., and Straughan, Robert D. (1999), Student Perceptions of Study Abroad Programs: A Survey of U.S. College and Universities, Marketing Education Review, 9 (1), pp. 29-36.

2. Balkan, Evan L (2003), All Students Deserve an Education without Borders, Community College Week, (September 29), pp. 4-5. 
3. Campbell, Kara, (2003) Theater Study Abroad Program Returns to Enrich Students, Utah Statesman, The Internet: http://www.utahstatesman.com/news/2003/04/14/Features/

Theater.Study.Abroad.Program.Returns.To.Enrich.Students.416889.shtml

4. Festervand, Troy A. and Tillery, Kenneth R., (2001), Short-term Study-Abroad Programs--A Professional Development Tool for International Business Faculty, Journal of Education for Business (November/December), pp. 106-111.

5. LaFranchi, Howard (2003) Why More Students are Studying Abroad, Christian Science Monitor, The Internet: http://www.freepublic.com/focus/f-news/966461/posts

6. Peden, Tony, (2001) Studying Abroad: The Experience, The Internet: http://www. abroadviewmagazine.com/archives/spring_01/studyabroad.html

7. Praetzel, Gary D. and Curcio, James (1996) Making Study Abroad a Reality for All Students, International Advances in Economic Research, 2 (2), pp. 174-182.

8. Toncar, Mark F. and Jane S. Reid (2004), Study Abroad: Business Student Perceptions and Preferences, Proceedings, Emerging Issues in Business and Technology, Ronald J. Bauerly, Paul C. Thistlethwaite, Dale W. Schofield, eds., October 28-30, Myrtle Beach, SC., 185-192. 
NOTES 